\title{
Production of $\alpha$-linolenic Acid by an Oleaginous Green Algae Acutodesmus obliquus Isolated from Malaysia
}

\author{
Fatin Syahirah Othman ${ }^{1}$ (D) , Haryati Jamaluddin ${ }^{2}(\mathbb{D})$, Zaharah Ibrahim ${ }^{2}$ (D) Hirofumi \\ Hara $^{1}$ (D) Nurul Ashyikin Yahya ${ }^{1}$, Koji Iwamoto ${ }^{1}$ (D) and Shaza Eva Mohamad ${ }^{3 *}$ (D) \\ ${ }^{1}$ Malaysia-Japan International Institute of Technology, Universiti Teknologi Malaysia, 54100, Jalan Sultan Yahya \\ Petra, Kuala Lumpur, Malaysia. ${ }^{2}$ Faculty of Science, Universiti Teknologi Malaysia, 81310, UTM Johor Bahru, \\ Johor, Malaysia. ${ }^{3}$ International Centre, Tokyo City University, 3-3-1 Ushikubo Nishi Tsuzuki-ku, Yokohama, \\ Kanagawa, 224-8851 Japan.
}

\begin{abstract}
The main purpose of this study is to provide information on the biochemical composition of the total lipid extract of three different native freshwater microalgae namely Acutodesmus obliquus CN01, Chlorella sp. Carolina-15-2069, and Chlorella vulgaris NIES-1269 at different growth phases, cultured under standardized conditions that will be useful for commercialization purposes due to the content of $\alpha$-linolenic acid (ALA), a type of omega-3 fatty acids. We monitored growth, biomass accumulation, chlorophyll content, lipid content and fatty acids composition in all three freshwater microalgae. In addition, this study seeks to throw some light on the lipid content of a newly isolated freshwater green alga Acutodesmus obliquus CNO1 which have shown to give significant quantities of ALA, an added nutritional value to this microalga oil. Acutodesmus obliquus CNO1 exhibited the fastest growth rate among the three microalgae used. Biomass was shown to be enhanced in the nitrogen enrichment medium. The outcomes from this study indicated that newly isolated Acutodesmus obliquus CNO1 from Malaysia cultured under normal condition showed fast growth rate with high lipid content and also high ALA content. Therefore, from this study, Acutodesmus obliquus CN01 was identified as species of choice to be further explored for its potential to produce omega-3 fatty acids.

Keywords: Acutodesmus obliquus, Chlorella sp., Chlorella vulgaris, Lipid, Malaysia.
\end{abstract}

\footnotetext{
*Correspondence: shaza@utm.my

(Received: 09 August 2019; accepted: 17 September 2019)
}

Citation: Fatin Syahirah Othman, Haryati Jamaluddin, Zaharah Ibrahim, Hirofumi Hara, Nurul Ashyikin Yahya, Koji Iwamoto and Shaza Eva Mohamad, Production of a-linolenic Acid by an Oleaginous Green Algae Acutodesmus obliquus Isolated from Malaysia, J Pure Appl Microbiol., 2019; 13(3):1297-1306. https://doi.org/10.22207/JPAM.13.3.01

(c) The Author(s) 2019. Open Access. This article is distributed under the terms of the Creative Commons Attribution 4.0 International License which permits unrestricted use, sharing, distribution, and reproduction in any medium, provided you give appropriate credit to the original author(s) and the source, provide a link to the Creative Commons license, and indicate if changes were made. 


\section{INTRODUCTION}

Polyunsaturated fatty acids (PUFA) are the essential nutrients that humans need to consume in order to obtain PUFA in their diet since humans cannot synthesise PUFA. Prominent derivative products of PUFA are omega- 3 fatty acids (or PUFA n-3) and omega- 6 fatty acids (or PUFA $n-6)^{1}$. Omega-3 fatty acids have first double bond located between the third and fourth carbon atom counting from the methyl end of the fatty $\mathrm{acid}^{2}$. The shortest chain of omega-3 fatty acids is $\alpha$-linolenic acid (ALA, C18:3, n-3) The main long chain of omega- 3 fatty acids $(\omega-3$ LC-PUFA) are eicosapentaenoic acid (EPA; 20:5n$3)$, docosapentaenoic acid (DPA; 22:5n-3) and docosahexaenoic acid (DHA; 22:6n-3) 4 .

Omega-3 fatty acids have a pivotal role in brain development, cardiovascular function and immune system regulation ${ }^{4}$. There is evidence that omega-3 fatty acids also play a crucial role in treating arteriosclerosis, cancer and rheumatoid arthritis $^{5}$.

In the new global economy, increase of the human population has become a central issue for the needs of new sources for omega-3 fatty acids. Currently, the main commercial source for omega-3 fatty acids is marine fish ${ }^{5}$. However, evidence suggests that marine fish is not sufficient for the world's requirement of omega-3 fatty acids. Fish may not be the best source of omega-3 fatty acids due to its scarcity, odour, geographical and seasonal variations in quality ${ }^{6}$. Besides, there is an increasing interest in recent years among vegetarians for omega- 3 fatty acids from non-animal sources ${ }^{7}$. Growing demand for new sources of omega-3 fatty acids is also a continuing safety concern within the accumulation of heavy metals and lipo-soluble compounds such as organic mercury compounds and polychlorinated biphenyls ( $P C B s$ ) from the contaminants in the marine fish oil?. A much-debated question is whether marine fish will be used as a source of food to humans or as a source for production of omega-3 fatty acids supplement to human for health care. Hence, several microalgae such as Chlorella sp. and Chlorella vulgaris have been studied due to their known ability to produce omega-3 fatty acids ${ }^{3,8}$.

Recently, microalga biomass has been attracting a lot of interest because of its rich source of nutrients such as omega- 3 fatty acids, omega 6 fatty acids, proteins, minerals and other essential nutrients ${ }^{9}$. There is a growing body of literature that recognises microalgae as a suitable alternative source of omega- 3 fatty acids due to their continuity of raw materials, easily developed in the tropics, not susceptible to chemical contamination ${ }^{1}$, being produced in a carefully controlled environment, and suitable for those following a vegetarian $\operatorname{diet}^{10}$.

Existing research recognizes Acutodesmus $\mathrm{sp}$. as one of the ideal oleaginous freshwater microalgal species for research due to luxurious growth $^{8}$ with easy cultivation ${ }^{11-21}$, highly immune to bacterial infection ${ }^{12}$, dominate other algal species and can flexibly adapt to wide range of environmental condition ${ }^{13}$. This present study, therefore, set out to assess biochemical composition of three different native freshwater microalgae with respect to different growth phases cultured under standardized conditions that might be useful for further commercial exploitation. Additionally, this present study seeks to throw some light on the lipid content of newly isolated freshwater green alga Acutodesmus obliquus that contain significant quantities of ALA after lipid accumulation, which could give nutritional added value to this microalgae oil.

\section{MATERIALS AND METHODS Microalgae strains}

The freshwater microalgae species are Chlorella sp. (Carolina-15-2069, Carolina Biological Supply Company, USA), Chlorella vulgaris (NIES1269, National Institute for Environmental Studies) and Acutodesmus obliquus (CN01, MJIITUTM, Malaysia). Chlorella sp. (Carolina-15-2069, Carolina Biological Supply Company, USA) was obtained from Carolina Biological Supply Company. Meanwhile, Chlorella vulgaris (NIES-1269, National Institute for Environmental Studies, Japan) was obtained from National Institute for Environmental Studies, Japan. Acutodesmus obliquus (CNO1, MJIIT-UTM, Malaysia) was obtained from a freshwater sampling site at Hulu Langat River near to Langat River Dam in Selangor, Malaysia by researchers from Universiti Teknologi Malaysia.

\section{Growth of microalgae}

Chlorella sp. (Carolina-15-2069, Carolina Biological Supply Company, USA) and Chlorella 
vulgaris (NIES-1269, National Institute for Environmental Studies, Japan) were cultured in BG-11 medium 22. Acutodesmus obliquus (CN01, MJIIT-UTM, Malaysia) was cultivated in AF6 medium $^{22}$. The $\mathrm{pH}$ of the BG-11 medium and AF6 medium were adjusted to $\mathrm{pH} 7.5$ and $\mathrm{pH}$ 6.6, respectively. Cultures were grown at $25^{\circ} \mathrm{C}$ for 12 $\mathrm{h}$ photoperiod with white fluorescent lamp at $80 \mu \mathrm{mol}$ photons $/ \mathrm{m}^{2} / \mathrm{s}$ with continuous aeration. The cultures were grown for 30 days otherwise stated.

The cultures with $10 \%(\mathrm{v} / \mathrm{v})$ inoculum size were grown separately under two conditions, which are under normal medium (BG-11, AF6) and with the addition of $4 \mathrm{mM}$ of sodium nitrate (nitrogen rich conditions) ${ }^{23}$ in normal medium to establish nitrogen enrichment medium in identifying the effects on biomass production.

The growth of the freshwater microalgae was monitored every other day at $750 \mathrm{~nm}$ optical density (OD) using UV-spectrophotometer (Hach DR 6000, Hach, U.S.A.). Specific growth rate ( $\mu$, day- ${ }^{1}$ ) for each strain was determined at the exponential growth phase ${ }^{24}$.

\section{Dry cell weight}

Dry cell weight was determined at different cultivation time points (10, 20, 30 days) adopting the method of Fan et al. ${ }^{5}$ Briefly, cultures were centrifuged at $3500 \mathrm{xg}$ for $10 \mathrm{~min}$. The pellet cells were then dried in the drying oven at $65^{\circ} \mathrm{C}$ for 24 hours. The dry cell weight was measured after drying the cell pellet at $65^{\circ} \mathrm{C}$ and was expressed as gram of dried weight per $1 \mathrm{ml}$ of medium ${ }^{5}$.

\section{Chlorophyll concentration measurement}

Chlorophyll concentration was measured every ten days. $1 \mathrm{ml}$ of algae culture was centrifuged at $4^{\circ} \mathrm{C}$ for 10 minutes at $16000 \times \mathrm{g}$. Supernatant was removed. $1.0 \mathrm{~mL}$ of absolute $(100 \%)$ methanol was added. The samples were vortexed and centrifuged again at $4^{\circ} \mathrm{C}$ for 10 minutes at 16000 $x \mathrm{~g}$. The OD of the supernatant was measured by spectrophotometer at $645 \mathrm{~nm}$ and $663 \mathrm{~nm}$ to identify the chlorophyll content, which was calculated and expressed as $\mu \mathrm{g} / \mathrm{mL}^{7}$.

\section{Lipid staining}

Pellet from $1 \mathrm{ml}$ of culture was washed twice with $1 \mathrm{~mL}$ of phosphate buffer saline (PBS). PBS was prepared by dissolving $8 \mathrm{~g} \mathrm{NaCl}, 0.2 \mathrm{~g} \mathrm{KCl}$, $1.44 \mathrm{~g} \mathrm{Na}_{2} \mathrm{HPO}_{4} * 12 \mathrm{H}_{2} \mathrm{O}$ and $0.24 \mathrm{~g} \mathrm{KH}_{2} \mathrm{PO}_{4}$ in 1000 $\mathrm{ml}$ distilled water and was autoclaved. After that, the cell suspension was diluted with distilled water to $1: 100$ serial dilutions for staining by Nile red (9-diethylamino-5-benzo[ $\alpha]$ zphenoxazinone). The staining stock solution was prepared by dissolving $0.5 \mathrm{mg}$ of nile red powder into $1 \mathrm{ml}$ of acetone. After adding $1.8 \mu \mathrm{L}$ Nile red stock solution to the diluted cell suspension, it was kept in the dark for 20 minutes to ensure that the pigment reacted towards the lipid in the algae. Then, the samples were assayed using fluorescence spectrometer (LS55, Perkin Elmer, USA) by recording the fluorescence intensity (a.u.). The excitation and emission wavelength used are $488 \mathrm{~nm}$ and 520 $\mathrm{nm}$, respectively ${ }^{25}$.

\section{Total Lipid Extraction}

The lipid was extracted according to the modified Folch's lipid extraction method ${ }^{26}$. $50 \mathrm{~mL}$ of algae suspension were harvested by centrifugation at $12,000 \times g$ for 5 minutes at $25^{\circ} \mathrm{C}$. Before the pellet was freeze-dried using freeze dryer (FDU-1200, Eyela, Japan) for 1 day, it was stored at $-80^{\circ} \mathrm{C}$. The freeze-dried cells were weighed and re-suspended in $6 \mathrm{~mL}$ methanolchloroform mixture (1:2 v/v). $100 \mu \mathrm{L}$ of C17 fatty acid (internal standard) with the concentration of $500 \mu \mathrm{g} / \mathrm{mL}$ was added to the crude lipid, which was then mixed by vortexing prior to centrifugation at $25^{\circ} \mathrm{C}$ for 10 minutes at $1000 \times \mathrm{g}$. The supernatant was removed and $1.25 \mathrm{~mL}$ of $0.1 \mathrm{M} \mathrm{KCl}$ was added to the new tube containing the supernatant, which was then mixed by vortexing for 30 seconds and centrifuged again at $25^{\circ} \mathrm{C}$ for 10 minutes at 1000 $\mathrm{x} g$. Lipid content in the bottom chloroform phase was transferred to the rotary evaporator (VC-15s, Taitec, Japan) for evaporation under vacuum for 2 hours to the constant weight. Lipid content in the microalgae cells was calculated by weighing the dried lipid extract obtained from the evaporation using the electronic scale and expressed as the percentage of dry cell weight.

\section{Analysis of Fatty Acid Content}

Fatty acid methyl esters (FAMEs) were extracted from the total intracellular lipid according to Kotajima et al. ${ }^{27} 4 \mathrm{~mL}$ of $0.1 \mathrm{~N}$ methanolic hydrochloric acid ( $\mathrm{MeOH}: \mathrm{HCl}$ ) was added to the dried lipid and kept in water at $100^{\circ} \mathrm{C}$ for 1 hour to obtain FAMEs from the saponification and methylesterification of the free fatty acids and acyl-groups in the lipids. Then, $4 \mathrm{~mL}$ of hexane was added to the cooled FAMEs sample to recover the resultant 
FAMEs with vigorous shaking for separating the two layers. The upper FAMEs containing layer was kept in a new micro centrifuge tube. The lower $\mathrm{MeOH}: \mathrm{HCl}$ phase, which is the remaining layer, was re-extracted with $2 \mathrm{~mL}$ distilled water and $2 \mathrm{~mL}$ hexane. The re-extracted upper FAMEs containing layer was combined with the first upper layer extracted that was kept earlier in the micro centrifuge tube and then transferred to rotary evaporator for evaporation under vacuum for 30 minutes. $300 \mu \mathrm{L}$ of hexane was added to the dried FAMEs. The solution was transferred into a glass vial for determining the fatty acid composition using gas chromatography.

\section{Gas Chromatography Analysis}

FAMEs were quantified and identified by gas chromatograph equipped with mass spectrometer detector (GC/MS: G 3171A, Agilent, USA) and a HP-5M5 column (Agilent). The carrier gas used was helium in a splitless mode with constant flow rate of $7.10 \mathrm{~mL} / \mathrm{min}$. The initial temperature was $100^{\circ} \mathrm{C}$ for $1 \mathrm{~min}$ then raised to $200^{\circ} \mathrm{C}$ at a ramping rate of $25^{\circ} \mathrm{C} / \mathrm{min}$ and held for 1 minute, which was then further increased to $250^{\circ} \mathrm{C}$ at a rate of $4^{\circ} \mathrm{C} / \mathrm{min}$ and held again for 7 minutes ${ }^{28}$. The FAMEs content was calculated according to the method of Corro et al. ${ }^{29}$ by comparing the peak area of the total FAME chromatogram with the peak area of internal standard (C17:0).

\section{RESULTS AND DISCUSSION Growth of microalgae}

Table 1 displays the specific growth rate of microalgae in normal medium and those in nitrogen enriched medium. The specific growth rate quantified the growth potential as a number indicating the number of times an organism

Table 1. Specific growth rate of microalgae in normal medium and nitrogen enriched medium

\begin{tabular}{|c|c|c|}
\hline \multirow[t]{2}{*}{ Microalgae } & \multicolumn{2}{|c|}{ Specific growth rate $\left(\mu\right.$, day $\left.^{-1}\right)$} \\
\hline & $\begin{array}{l}\text { Normal } \\
\text { medium }\end{array}$ & $\begin{array}{l}\text { Nitrogen enriched } \\
\text { medium }\end{array}$ \\
\hline $\begin{array}{l}\text { Acutodesmus } \\
\text { obliquus CN01 }\end{array}$ & 0.0781 & 0.0931 \\
\hline $\begin{array}{l}\text { Chlorella sp. } \\
\text { Carolina-15-2069 }\end{array}$ & 0.0581 & 0.0690 \\
\hline $\begin{array}{l}\text { Chlorella vulgaris } \\
\text { NIES-1269 }\end{array}$ & 0.0533 & 0.0721 \\
\hline
\end{tabular}

reproduces in the time unit ${ }^{30}$. Acutodesmus obliquus CNO1 was shown to exhibit the fastest growth rates, which are 0.0781 /day (normal media) and 0.0931/day (nitrogen enriched media) for both media compared to Chlorella sp. Carolina-15-2069 (0.0581/day and 0.0690/day) and Chlorella vulgaris NIES-1269 (0.0533/day and $0.0721 /$ day). From previous study, it was shown that high doubling time corresponds to a low specific growth rate ${ }^{31}$. Mujtaba et al. ${ }^{23}$ reported that Acutodesmus sp. has a tendency for easy cultivation and has a fast growth rate. Fast and high growth rate encourages high biomass productivity, competitive advantage over competing species and reduces required culture area ${ }^{31}$.

\section{Dry cell weight}

Dry cell weight of the microalgae was measured to identify the differences in biomass production by the normal medium and nitrogen enrichment medium. Fig. 1a and Fig. 1b illustrate the dry cell weight of microalgae in normal medium and in nitrogen enriched medium, respectively.

Fig. $1 \mathrm{a}$ and $1 \mathrm{~b}$ indicate enhanced biomass production in the nitrogen enrichment medium. This was due to high nitrogen concentrations in the medium ( $4 \mathrm{mM}$ of sodium nitrate) that can significantly enhance the biomass production ${ }^{32}$. Acutodesmus obliquus CN01 has the highest biomass production at day 20 in normal AF6 medium $(0.0051 \mathrm{~g} / \mathrm{mL})$ and nitrogen enrichment medium $(0.0066 \mathrm{~g} / \mathrm{mL}$ ) compared to Chlorella sp. Carolina-15-2069 and Chlorella vulgaris NIES-1269. These results are consistent with those of other studies and suggest that Acutodesmus obliquus CN01 has a fast growth rate which promotes high biomass productivity that can reduce cost for large-scale lipid production ${ }^{33}$. Biomass for Acutodesmus obliquus CN01 was shown to sharply increased during 10-30 days of cultivation in nitrogen enrichment medium if compared to the normal AF6 medium.

For normal AF6 medium, the maximum production of biomass for Chlorella $\mathrm{sp}$. Carolina-15-2069 (0.0022 g/mL) and Chlorella vulgaris NIES-1269 (0.0033 g/mL) was obtained at day 30 (Fig. 1a and 1b). For nitrogen enrichment medium, the maximum production of biomass for Chlorella sp. Carolina-15-2069 (0.0034 g/mL) was at day 30 while Chlorella vulgaris NIES-1269 $(0.0041 \mathrm{~g} / \mathrm{mL})$ at day 30 . As shown in Fig. 1a and 


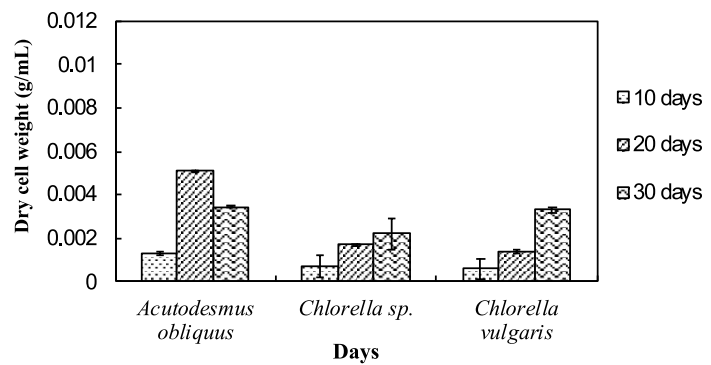

Fig. 1a. Dry cell weights of microalgae in normal medium.

Fig. $1 b$, the maximum algal biomass for these three microalgae was obtained after 10-30 days of cultivation. The results, as shown in Fig. 1a and $1 b$, indicated that the medium enrichment and the age of the microalgae culture can affect the biomass production.

\section{Chlorophyll concentration measurement}

The health of photosynthetic cells in microalgae are assessed by measuring the chlorophyll content of microalgae ${ }^{7}$. In summary, from Fig. 2, these results show that the highest total chlorophyll content was observed in Chlorella sp. Carolina-15-2069 (21 mg/L) followed by Chlorella vulgaris NIES-1269 (13 mg/L) and Acutodesmus obliquus CN01 ( $3 \mathrm{mg} / \mathrm{L}$ ). Interestingly, the chlorophyll content was observed to increase with cultivation time. These results are in line with those of previous studies. Chlorophyll is one of the cellular compounds that is used for estimating biomass of microalgae in culture and can be used to measure growth where the chlorophyll content per cell is increased due to the reduction of the irradiance into the culture by the shading effect produced by the high cellular density of the culture ${ }^{34}$. On day 30, the total chlorophyll content of Acutodesmus obliquus CNO1 suddenly decreased to $1.2 \mathrm{mg} / \mathrm{L}$. This could be due to nutrient depletion.

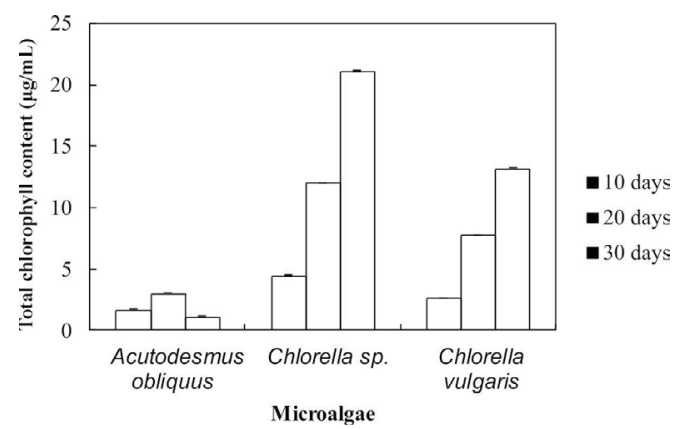

Fig. 2. Total chlorophyll content in microalgae.

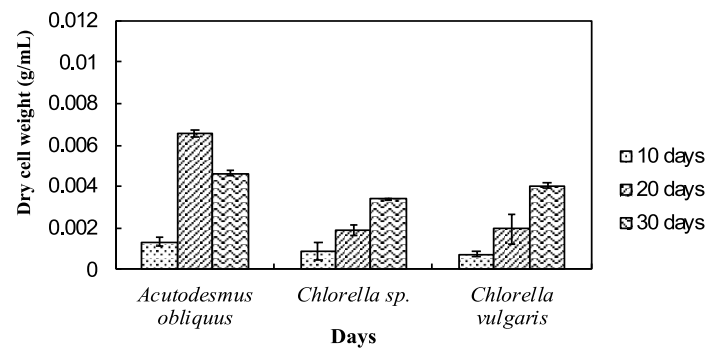

Fig. 1b. Dry cell weights of microalgae in nitrogen enrich medium.

\section{Nile red staining}

Nile red is a red fluorescent lipophilic dye $\mathrm{e}^{35}$ where it fluoresces indicates the present amount of neutral lipid ${ }^{36}$. The colour of the Nile red able to penetrate cell walls, cytoplasmic membrane and dissolve in the intracellular neutral and polar lipids to give the desired yellow fluorescence colour and will give a red fluorescence colour without staining cells ${ }^{37}$. From the lipid analysis using Nile red staining, Chlorella sp. Carolina-15-2069 showed strongest fluorescence signals at day 20, whereas both Chlorella vulgaris NIES-1269 and Acutodesmus obliquus CNO1 yielded strongest fluorescence emissions at day 30 (Fig. 3).

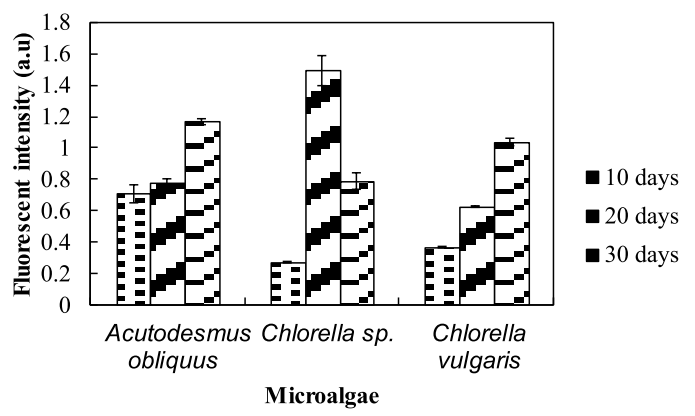

Fig. 3. Nile red staining results of microalgae.

The current study found that after 20 days, the microalgae was still able to accumulate neutral lipid. This is an interesting outcome. High fluorescence intensities indicated high neutral lipid content in these organisms. Another interesting finding is the lipid content changed along with growth. Measuring lipid content by Nile red staining is the rapid ${ }^{36}$, simplest and cost-effective method $^{35}$.

\section{Lipid contents}

The amount of lipid in microalga was quantified to identify the lipid content in the microalgae. Lipids are synthetized as energy 
and carbon reserve to stress conditions and accumulated as triacylglycerols (TAG) in the cytoplasm ${ }^{38}$. Besides, lipid production was enhanced by a number of factors including aeration to the culture, increases in carbon dioxide supply and depleted with a depletion of carbon source in the medium ${ }^{23}$. The most striking result to emerge from the data is that the lipid content for Acutodesmus obliquus CN01 was the highest (47\%) if compared to the other two algae (Fig. 4). The lipid content value in this study was the highest lipid content reported for Acutodesmus obliquus CN01 growth under normal condition ${ }^{12,19,39}$. This result is somewhat counterintuitive. Acutodesmus $\mathrm{sp}$. is of interest as Acutodesmus sp. was the ideal species for lipid accumulation ${ }^{7,40,41,42}$. It has been reported that low nutrient concentration and good penetration of light to the individual cells would cause photosynthesis to generate more metabolic flux that will be channelled to lipid accumulation in Acutodesmus sp. ${ }^{7}$

There was a significant difference in lipid class and fatty acid composition of microalga cells at different growth phase due to variations in culture conditions including nutrient status (nitrogen or phosphorus starvation) ${ }^{37}$, temperature, salinity, $\mathrm{pH}$, photoperiod, light intensity and light quality ${ }^{6}$. Prior studies have noted that reduction in lipid content of Chlorella sp. Carolina-15-2069 and Chlorella vulgaris NIES-1269 are due to triglyceride utilization during cell division cycle, mortality of

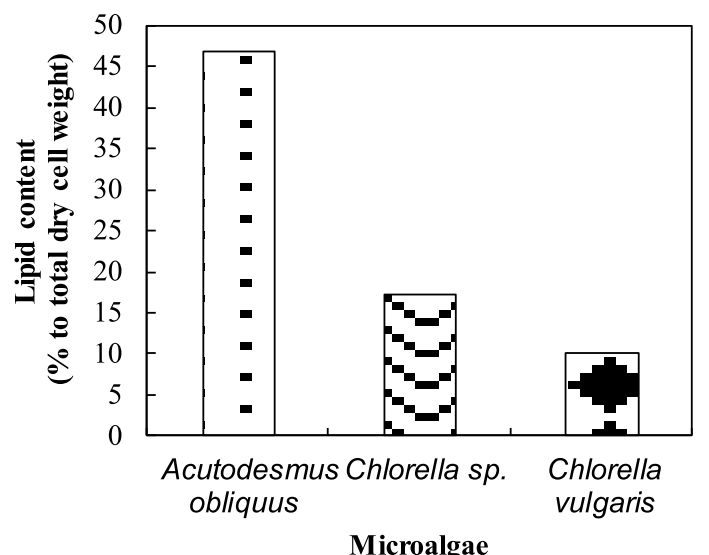

Fig. 4. Lipid content of Acutodesmus obliquus CNO1 (percentage to total dry cell weight). Dotted bar: Acutodesmus obliquus CN01, wavy line bar: Chlorella sp. Carolina-15-2069, solid diamond: Chlorella vulgaris NIES-1269. algal cells at later stage, and also depletion of nutrients in the culture medium ${ }^{21}$.

\section{FAMEs profiles}

The percentage of fatty acid composition in the three species of microalgae used in this study was summarised in Table 2. Fatty acids were extracted after 15 days of cultivation and analysed by $\mathrm{GC} / \mathrm{MS}$ for the identification of the fatty acids profile in the freshwater microalgae. A possible explanation for this is that longer cultivation time was beneficial for the accumulation of unsaturated fatty acids ${ }^{21}$. As illustrated in Table 2, fatty acids that were synthesized have chain lengths that range from $\mathrm{C} 16$ to $\mathrm{C} 18$.

These result suggest that saturated fatty acid (SFA) content was higher in Chlorella sp. Carolina-15-2069 if compared to the other two microalgae. Surprisingly, monounsaturated fatty acid (MUFA) was not found in Chlorella sp. Carolina-15-2069 and Chlorella vulgaris NIES-1269. According to data obtained from Table 2, we can conclude that Chlorella vulgaris NIES-1269 has the highest amount of polyunsaturated fatty acid (PUFA) followed by Chlorella sp. Carolina-15-2069 and Acutodesmus obliquus CN01. Variations that were observed in the fatty acid amount in each microalga are possibly due to extraction technique, lipolysis due to long term storage of microalgal paste and culture condition of the microalgae such as temperature, nutrients, dilution rate, carbon dioxide concentration and growth phase of microalgae at the time of harvest ${ }^{2}$.

In the present study, Acutodesmus obliquus CNO1 showed high amount of $\alpha$-linolenic acid (ALA), palmitic acid, and oleic acid. The results of this study also indicated that the main fatty acids found in Chlorella sp. Carolina-15-2069 were palmitic acid, ALA, and hexadecatrienoic acid. Chlorella vulgaris NIES-1269 consisted of mostly ALA, palmitic acid, and linoleic acid. It is apparent from this table that ALA and palmitic acid were the main components of the fatty acid profile in these three microalgae.

The highest amount of ALA was found in Acutodesmus obliquus CNO1 (38\%) followed by Chlorella vulgaris NIES-1269 (35\%), and Chlorella sp. Carolina-15-2069 (17.9\%). Another important finding was that ALA content in Acutodesmus obliquus CNO1 reported in this study was higher than other study, ${ }^{6,9}$. It has been suggested that 
Table 2. Fatty acid profile (FA) (percentage to total fatty acids) of freshwater microalgae

\begin{tabular}{|c|c|c|c|c|}
\hline Fatty acids & Common name & $\begin{array}{l}\text { Acutodesmus } \\
\text { obliquus CN01 }\end{array}$ & $\begin{array}{c}\text { Chlorella sp. } \\
\text { Carolina-15-2069 }\end{array}$ & $\begin{array}{c}\text { Chlorella vulgaris } \\
\text { NIES-1269 }\end{array}$ \\
\hline \multicolumn{5}{|l|}{ Saturated } \\
\hline C16:0 & Palmitic acid & $32.4 \pm 2$ & $33.9 \pm 3.7$ & $25.7 \pm 0.8$ \\
\hline C18:0 & Stearic acid & ND & ND & $8.7 \pm 0.3$ \\
\hline Sum & & $32.4 \pm 2$ & $33.9 \pm 3.7$ & $34.4 \pm 1.1$ \\
\hline \multicolumn{5}{|c|}{ Monounsturated } \\
\hline C18:1 & Oleic acid & $32.0 \pm 2$ & ND & ND \\
\hline Sum & & $32.0 \pm 2$ & ND & ND \\
\hline \multicolumn{5}{|c|}{ Polyusaturated } \\
\hline $\mathrm{C} 16: 2(n-6)$ & $\begin{array}{l}\text { Hexadecadienoic } \\
\text { acid }\end{array}$ & ND & $13.1 \pm 1.45$ & ND \\
\hline C16:3 (n-3) & $\begin{array}{l}\text { Hexadecatrieoic } \\
\text { acid }\end{array}$ & $7.4 \pm 0.45$ & $17.3 \pm 1.9$ & $6.1 \pm 0.2$ \\
\hline C16:4 & & ND & ND & $5.9 \pm 0.45$ \\
\hline C18:2 (n-6) & Linoleic acid & $13.6 \pm 0.85$ & $11.6 \pm 1.25$ & $12.8 \pm 0.4$ \\
\hline C18:3(-3) & $\alpha$-linolenic acid & $38.0 \pm 13.5$ & $17.9 \pm 6.55$ & $35.4 \pm 1.1$ \\
\hline Sum & & $32.0 \pm 14.8$ & $59.9 \pm 11.15$ & $60.2 \pm 2.15$ \\
\hline
\end{tabular}

$\mathrm{ND}=$ not detected

ALA is a precursor or starting molecule for the synthesis of EPA and DHA ${ }^{43}$ and vital for normal development of infant's brains and nervous systems $\mathrm{s}^{3}$. It is interesting to note that in this study, the most compelling finding is Acutodesmus obliquus $\mathrm{CNO}$ 1 has a fast growth rate with a high lipid content and also high ALA content compared to the other two species of microalgae tested. This is an encouraging and positive result which provide important insights into Acutodesmus obliquus CNO1 as another significant source of nutraceuticals supplements especially ALA and has an extra advantage than the other two microalgae (Chlorella sp. Carolina-15-2069 and Chlorella vulgaris NIES-1269) for its easy upscale. This result is somewhat is counterintuitive. Acutodesmus obliquus CNO1 that was isolated from Malaysia was shown to well adapt to the temperature in Malaysia, which can reduce the upscale cost if to be used for production purposes. Apart from ALA, palmitic acid which is another main component of the fatty acid profile in these three microalgae has an outstanding antioxidant activity ${ }^{44}$ and has been identified as antitumor agent ${ }^{45}$.

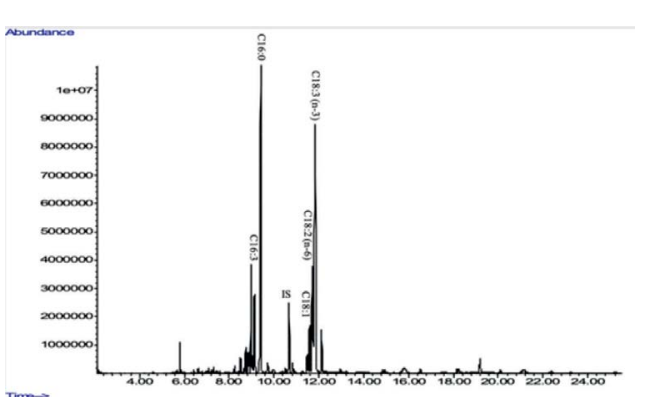

Fig. 5a. GC-MS chromatograms of FAME derived from freeze-dried biomass of freshwater green algae Acutodesmus obliquus CNO1 (see Table 2 for peak identification). "Heptadecanoic acid (C17:0) was used as an internal standard.

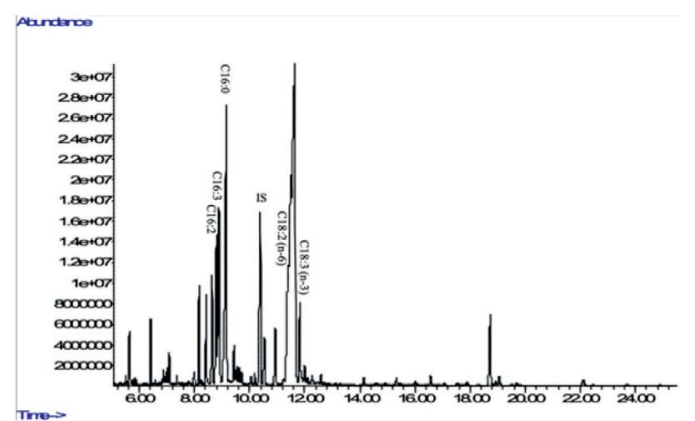

Fig. 5b. GC-MS chromatograms of FAME derived from freeze-dried biomass of freshwater green algae Chlorella sp. Carolina-15-2069 (see Table 2 for peak identification). "Heptadecanoic acid (C17:0) was used as an internal standard. 


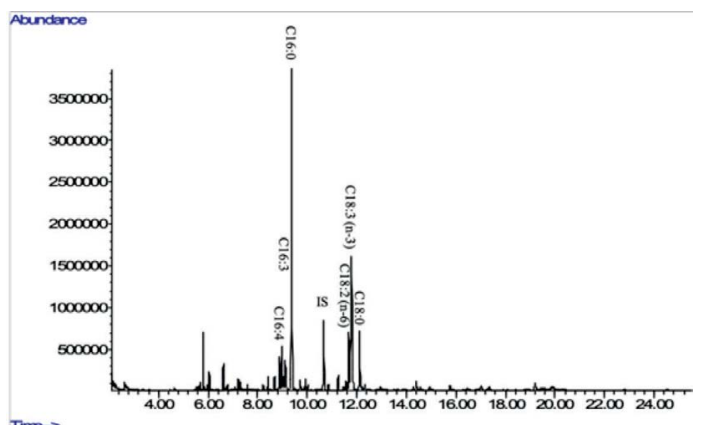

Fig. 5c. GC-MS chromatograms of FAME derived from freeze-dried biomass of freshwater green algae Chlorella vulgaris NIES-1269 (see Table 2 for peak identification). *Heptadecanoic acid (C17:0) was used as an internal standard.

\section{CONCLUSION}

The purpose of this study is to provide information on the biochemical composition of the total lipid extracted from freshwater microalgae. From this study, newly isolated Acutodesmus obliquus CN01 from Malaysia exhibited fast growth rate with a high lipid content and also high ALA content compared to Chlorella sp. Carolina-15-2069 and Chlorella vulgaris NIES-1269. Further research on Acutodesmus obliquus CNO1 is well underway in defining its ability to yield omega-3 fatty acids.

\section{ACKNOWLEDGEMENTS}

The authors fully acknowledge the Ministry of Higher Education (MOHE), MalaysiaJapan International Institute of Technology and Universiti Teknologi Malaysia for the fund, which made this important study viable and effective.

\section{AUTHORS' CONTRIBUTION}

All authors listed have made a substantial, direct and intellectual contribution to the work, and approved it for publication.

\section{CONFLICT OF INTEREST}

The authors declares that there is no conflict of interest.

\section{FUNDING}

This study was also supported by a grantin-aid from MJIIT Takasago Education and Research Grant (Vote No. PY/2015/05518) sponsored by

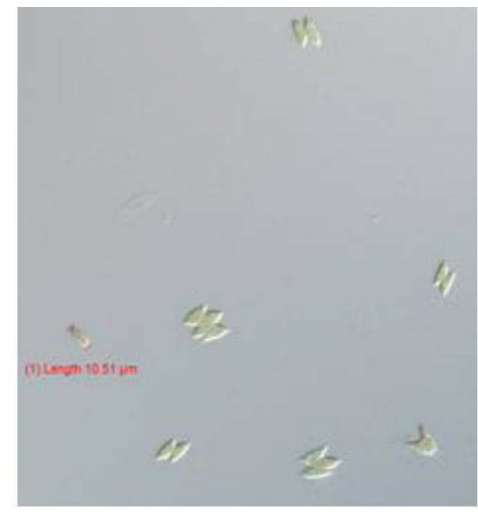

Fig. 6a. Morphological observation of Acutodesmus obliquus CNO1 with 40X magnification.

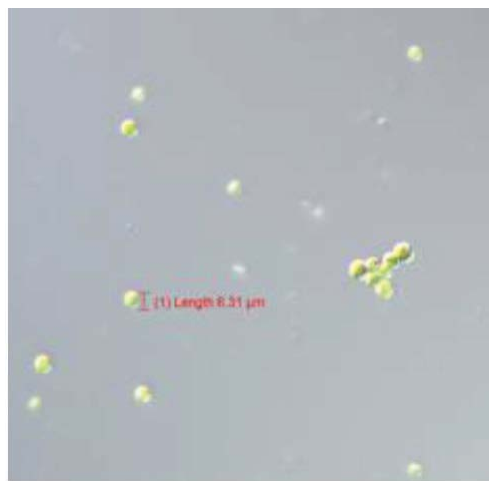

Fig. 6b. Morphological observation of Chlorella sp. Carolina-15-2069 with 40X magnification.

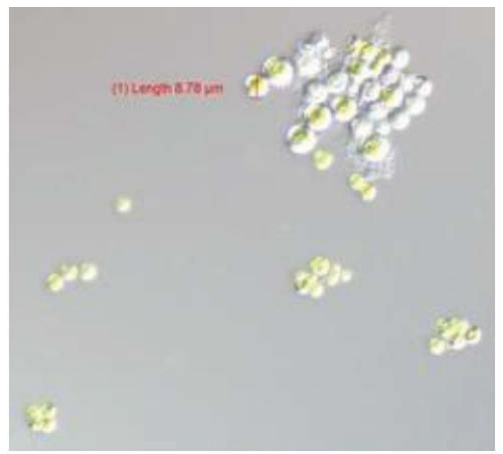

Fig. 6c. Morphological observation of Chlorella vulgaris NIES-1269 with 40X magnification.

Takasago Thermal Engineering Co. Ltd from 2015 to 2017.

\section{DATA AVAILABILITY}

All datasets obtained or studied during this study are incorporated in the manuscript. 


\section{ETHICS STATEMENT}

This article does not contain any studies with human participants or animals performed by any of the authors.

\section{REFERENCES}

1. Abyor N., Dessy A., Hady H. Potential production of polyunsaturated fatty acids from microalgae. Int. J. Sci. Eng., 2011; 2(1): 13-16.

2. Ryckebosch E., Bruneel C., Muylaert K., Foubert I. Microalgae as an alternative source of omega-3 long chain polyunsaturated fatty acids. Lipid Technol., 2012; 24(6): 128-130. https://doi.org/10.1002/ lite. 201200197

3. Sayeda M.A., Ali G.H., El-Baz F.K. Potential production of omega fatty acids from microalgae. Int J Pharm Sci Rev Res., 2015; 34(2): 210-215.

4. Liu B., Ertesvig H., Aasen I.M., Vadstein O., Brautaset T., Heggeset T.M.B. Draft genome sequence of the docosahexaenoic acid producing thraustochytrid Aurantiochytrium sp. T66. Genomics Data, 2016; 8: 115-116. https://doi.org/10.1016/j.gdata.2016.04.013

5. Fan K.W., Chen F., Jones E.B., Vrijmoed L.L. Eicosapentaenoic and docosahexaenoic acids production by and okara-utilizing potential of thraustochytrids. J. Ind. Microbiol. Biotechnol., 2001; 27(4): 199-202. https://doi.org/10.1038/ sj.jim.7000169

6. Liu C.P., Lin L.P. Ultrastructural study and lipid formation of Isochrysis sp. CCMP1324. Botan Bull. Aca., 2001; 42.

7. Tsai H.P., Chuang L.T., Chen C.N.N. Production of long chain omega-3 fatty acids and carotenoids in tropical areas by a new heat-tolerant microalga Tetraselmis sp. DS3. Food Chem., 2016; 192: 682-690. https://doi. org/10.1016/j.foodchem.2015.07.071

8. Makareviciene V., Andrulevivi t] V., Skorupskait] V., Kasperovivien J. Cultivation of microalgae Chlorella sp. and Scenedesmus sp. as a potentional biofuel feedstock. Environ Res Eng Manag, 2011; 57(3): 21-7.

9. Tokusoglu O. Biomass nutrient profiles of three microalgae: Spirulina platensis, Chlorella vulgaris, and Isochrysis galbana. J. Food Sci., 2003; 68(4): 11441148. https://doi.org/10.1111/j.1365-2621.2003. tb09615.x

10. Winwood R.J. Recent developments in the commercial production of DHA and EPA rich oils from micro-algae. OCL, 2013; 20(6): D604. https://doi.org/10.1051/ ocl $/ 2013030$

11. Han S.F., Jin W., Abomohra A.E., Zhou X., Tu R., Chen C., Chen H., Gao S. H., Wang Q. Enhancement of lipid production of Scenedesmus obliquus cultivated in municipal wastewater by plant growth regulator treatment. Waste Biomass Valori, 2018; 1-7. https:// doi.org/10.1007/s12649-018-0314-x

12. Liu J., Yuan C., Hu G., Li F. Effects of light intensity on the growth and lipid accumulation of microalga Scenedesmus sp. 11-1 under nitrogen limitation. Appl Biochem Biotechnol, 2012; 166(8): 2127-2137. https:// doi.org/10.1007/s12010-012-9639-2
13. Mandotra S. K., Kumar P., Suseela M. R., Ramteke P. W. Fresh water green microalga Scenedesmus abundans: a potential feedstock for high quality biodiesel production. Bioresour. Technol., 2014; 156: 42-7. https://doi.org/10.1016/j.biortech.2013.12.127

14. Martinez M.E., Jimenez J.M., El Yousfi F. Influence of phosphorus concentration and temperature on growth and phosphorus uptake by the microalga Scenedesmus obliquus. Bioresour. Technol., 1999; 67(3): 233-40. https://doi.org/10.1016/S0960-8524(98)00120-5

15. Mujtaba G., Choi W., Lee C.G., Lee K. Lipid production by Chlorella vulgaris after a shift from nutrient-rich to nitrogen starvation conditions. Bioresour. Technol., 2012; 123: 279-283. https://doi.org/10.1016/j. biortech.2012.07.057

16. Salama E.S., Kim H.C., Abou-Shanab R.A., Ji M.K., Oh Y.K., Kim S.H., Jeon B.H. Biomass, lipid content, and fatty acid composition of freshwater Chlamydomonas mexicana and Scenedesmus obliquus grown under salt stress. Bioprocess Biosyst. Eng., 2013; 36(6): 827-33. https://doi.org/10.1007/s00449-013-0919-1

17. Wu C., Wang W., Yue L., Yang Z., Fu Q., Ye Q. Enhancement effect of ethanol on lipid and fatty acid accumulation and composition of Scenedesmus sp. Bioresour. Technol., 2013; 140: 120-125. https://doi. org/10.1016/j.biortech.2013.04.079

18. Xin L., Hong-Ying H., Jia Y. Lipid accumulation and nutrient removal properties of a newly isolated freshwater microalga, Scenedesmus sp. LX1, growing in secondary effluent. New Biotechnol, 2010; 27(1): 59-63. https://doi.org/10.1016/j.nbt.2009.11.006

19. Xin L., Hong-ying H., Ke G., Jia Y. Growth and nutrient removal properties of a freshwater microalga Scenedesmus sp. LX1 under different kinds of nitrogen sources. Ecol. Eng., 2010; 36(4): 379-81. https://doi. org/10.1016/j.nbt.2009.11.006

20. Xin L., Hong-Ying H., Ke G., Ying-Xue S. Effects of different nitrogen and phosphorus concentrations on the growth, nutrient uptake, and lipid accumulation of a freshwater microalga Scenedesmus sp. Bioresour. Technol., 2010; 101(14): 5494-500. https://doi. org/10.1016/j.biortech.2010.02.016

21. Xin L., Hong-Ying H., Yu-Ping Z. Growth and lipid accumulation properties of a freshwater microalga Scenedesmus sp. under different cultivation temperature. Bioresour Technol, 2011; 102(3): 30983102. https://doi.org/10.1016/j.biortech.2010.10.055 22. Kawachi M., Ishimoto M., Mori F., Yumoto K., Sato M. MCC-NIES list of strains: microalgae, endangered macroalgae and protists, 9th ed. Microbial culture collection at National Institute for Environmental Studies, Tsukuba, 2013.

23. Mujtaba G., Choi W., Lee C. G., Lee K. Lipid production by Chlorella vulgaris after a shift from nutrient-rich to nitrogen starvation conditions. Bioresour. Technol., 2012; 123: 279-283. https://doi.org/10.1016/j. biortech.2012.07.057

24. Praharyawan S., Rahman D. Y., Susilaningsih D. Characterization of lipid productivity and fatty acid profile of three fast-growing microalgae isolated from Bengkulu for possible use in health application. J. Trop. 
Life Sci., 2016; 6: 79-85. https://doi.org/10.11594/ jtls.06.02.03

25. Zalogin T.R., Pick U. Azide improves triglyceride yield in microalgae. Algal. Res., 2014; 3: 8-16. https://doi. org/10.1016/j.algal.2013.12.002

26. Folch J., Lees M., Stanley G.S.A simple method for the isolation and purification of total lipids from animal tissues. J. Biol. Chem., 1957; 226(1): 497-509.

27. Kotajima T., Shiraiwa Y., Suzuki I. Functional screening of a novel 15 fatty acid desaturase from the coccolithophorid Emiliania huxleyi. Biochim Biophys. Acta., 2014; 1841(10): 1451-1458. https://doi. org/10.1016/j.bbalip.2014.07.010

28. Van Wychen S., Ramirez K., Laurens L.M.L. Determination of total lipids as fatty acid methyl esters (FAME) by in situ transesterification: Laboratory Analytical Procedure (LAP) (No. NREL/TP-5100-60958). National Renewable Energy Lab.(NREL), Golden, CO (United States), 2016. https://doi.org/10.1016/j. bbalip.2014.07.010

29. Corro G., Tellez N., Jimenez T., Tapia A., Banuelos F., Vazquez-Cuchillo $O$. Biodiesel from waste frying oil. Two step process using acidified $\mathrm{SiO}^{2}$ for esterification step. Catal Today, 2011; 166: 116-122. https://doi. org/10.1016/j.cattod.2010.09.011

30. Microalgal Growth Kinetics. http://w3.ual. es/ jfernand/MBio70411204/Lesson2/L2.1.html, Accessed 3 april 2017.

31. Griffiths M.J., Harrison S.T. Lipid productivity as a key characteristic for choosing algal species for biodiesel production. J. Appl. Phycol., 2009; 21(5): 493-507. https://doi.org/10.1007/s10811-008-9392-7

32. Minhas A.K., Hodgson P., Barrow C.J., Adholeya A. $A$ review on the assessment of stress conditions for simultaneous production of microalgal lipids and carotenoids. Front Microbiol., 2016; 7: 546. https:// doi.org/10.3389/fmicb.2016.00546

33. El-Sheekh M., Abomohra A.E.F., Hanelt D. Optimization of biomass and fatty acid productivity of Scenedesmus obliquus as a promising microalga for biodiesel production. World J. Microbiol. Biotechnol., 2013; 29(5): 915-922. https://doi.org/10.1007/s11274-0121248-2

34. Melina I.S.S., Arunachalam K., Nair B.B., Jayalakshmy. Biochemical characterization of eight marine microalgae grown in batch cultures. J Algal Biomass Utilization, 2016; 7(3): 19-41.

35. Alemבn-Nava G.S., Cuellar-Bermudez S.P., Cuaresma M., Bosma R., Muylaert K., Ritmann B. E., Parra R. How to use nile red, a selective fluorescent stain for microalgal neutral lipids. J Microbiol. Methods, 2016; 128: 74-79. https://doi.org/10.1016/j. mimet.2016.07.011
36.

Held P., Raymond K. Determination of algal cell lipids using nile red-using microplates to monitor neutral lipids in Chlorella Vulgaris. Biofuel. Res., 2011; 8: 1-5.

37. Rattanapoltee P., Kaewkannetra P. Nile red, an alternative fluorescence method for quantification of neutral lipids in microalgae. Int. J. Biotechno.l Bioeng., 2013; 7(9): 889-893.

38. Aliman-Nava G.S., Muylaert K., Bermudez S.P.C., Depraetere O., Rittmann B., Parra-Salda var R., Vandamme D.. Two-stage cultivation of Nannochloropsis oculata for lipid production using reversible alkaline flocculation. Bioresour. Technol., 2017; 226: 18-23. https://doi.org/10.1016/j. biortech.2016.11.121

39. Ho S.H., Chen C.Y., Chang J.S. Effect of light intensity and nitrogen starvation on $\mathrm{CO} 2$ fixation and lipid/ carbohydrate production of an indigenous microalga Scenedesmus obliquus CNW-N. Bioresour. Technol., 2012; 113: 244-252. https://doi.org/10.1016/j. biortech.2011.11.133

40. Renuka N., Guldhe A., Singh P., Bux F. Combined effect of exogenous phytohormones on biomass and lipid production in Acutodesmus obliquus under nitrogen limitation. Energ Convers Manage, 2018; 168: 522-8. https://doi.org/10.1016/j.biortech.2011.11.133

41. Sirikhachornkit A., Suttangkakul A., Vuttipongchaikij S., Juntawong P. De novo transcriptome analysis and gene expression profiling of an oleaginous microalga Scenedesmus acutus TISTR8540 during nitrogen deprivation-induced lipid accumulation. Sci. Rep., 2018; 8(1): 3668. https://doi.org/10.1016/j. biortech.2011.11.133

42. Zhang Y., He M., Zou S., Fei C., Yan Y., Zheng S., Rajper A. A., Wang C. Breeding of high biomass and lipid producing Desmodesmus sp. by ethylmethane sulfonate-induced mutation. Bioresour. Technol., 2016; 207: 268-75. https://doi.org/10.1016/j. biortech.2016.01.120

43. Kapoor R., Patil U. K. Importance and production of omega-3 fatty acids from natural sources. Int. Food Res., 2011; 18(2).

44. Vijsaral E.D., Arumugam S. GC-MS analysis of bioactive constituents of Indigofera suffruticosa leaves. J. Chem. Pharm. Res., 2014; 6: 294-300.

45. Alencar D.B., Diniz J.C., Rocha S.A., Pires-Cavalcante K., Lima R.L., Sousa K.C., Freitas J.O., Bezerra R.M., Baracho B.M., Sampaio A.H., Viana F.A. Fatty acid composition from the marine red algae Pterocladiella capillacea (SG Gmelin) Santelices \& Hommersand 1997 and Osmundaria obtusiloba (C. Agardh) RE Norris 1991 and its antioxidant activity. Anais da Academia Brasileira de Ci7ncias, 2018; 90(1): 449-59. https://doi. org/10.1590/0001-3765201820160315 